\title{
Detailed experimental and theoretical investigation and comparison of the cascadability of semiconductor optical amplifier gates and gain-clamped semiconductor optical amplifier gates
}

Danielsen, Søren Lykke; Hansen, Peter Bukhave; Wolfson, David; Mikkelsen, Benny; Stubkjær, Kristian; Emery, J.Y.; Pommereau, F; Renaud, M.

Published in:

Technical Digest Optical Fiber Communication Conference and Exhibit

Link to article, DOI:

10.1109/OFC.1998.657187

Publication date:

1998

Document Version

Publisher's PDF, also known as Version of record

Link back to DTU Orbit

Citation (APA):

Danielsen, S. L., Hansen, P. B., Wolfson, D., Mikkelsen, B., Stubkjær, K., Emery, J. Y., Pommereau, F., \& Renaud, M. (1998). Detailed experimental and theoretical investigation and comparison of the cascadability of semiconductor optical amplifier gates and gain-clamped semiconductor optical amplifier gates. In Technical Digest Optical Fiber Communication Conference and Exhibit (pp. 41-42). IEEE.

https://doi.org/10.1109/OFC.1998.657187

\section{General rights}

Copyright and moral rights for the publications made accessible in the public portal are retained by the authors and/or other copyright owners and it is a condition of accessing publications that users recognise and abide by the legal requirements associated with these rights.

- Users may download and print one copy of any publication from the public portal for the purpose of private study or research.

- You may not further distribute the material or use it for any profit-making activity or commercial gain

- You may freely distribute the URL identifying the publication in the public portal 
offers low cost, compact devices, with a low power consumption. In addition, fast switching and operation at wavelengths outside of the $1.55-\mu \mathrm{m}$ band are possible. These advantages open the way towards the use of optical amplifiers in new as well as in existing applications.

Applications under consideration for SOAs are short- and middistance digital communication systems, for instance local area, ring and/or access networks. In such systems, amplifiers are necessary to compensate for the losses due to signal distribution and multiplexing, in addition to fiber losses. Due to their high on-off ratio's combined with fast switching characteristics, SOAs can also be used as signal switching elements, contributing greatly to the functionality of these networks. Looking further ahead, SOA technology can be applied to implement all-optical signal processing functions, such as add-drop multiplexing and wavelength conversion in wavelength-division multiplexing (WDM) systems. In the field of analog community antenna television communications, SOAs are also gaining ground. Here, the availability of $1.3-\mu \mathrm{m}$ wavelength amplificrs has stimulated the development of analog-grade SOAs. Finally, SOAs are being applied in broadband light sources and sensing applications, offering respectable performance improvements over conventional techniques.

The key device parameters that determine the performance of SOAs in communication systems are gain, saturation power, and noise figure. They depend on the material composition and design of the amplifier active layer, on its length, and on its operating conditions (temperature and current). Adjusting these parameters leads to optimization of the amplifier for different applications. Ideally, high saturation powers and low noise figures are required; the gain is chosen based on the application. Progress in the field of SOAs has lead to the availability of amplifiers with fiber-coupled saturation powers in the order of $+15 \mathrm{dBm}$, noise figures around $7 \mathrm{~dB}$ and gains in excess of $30 \mathrm{~dB} .^{1}$

In order to meet the requirements imposed by many applications, a number of performance issues must be addressed. Most important is that of signal distortion, which arises from the fast gain recovery time inherent to compound semiconductor devices. By "gain clamping" the amplifier, a constant optical gain is created over a wide range of signal power. ${ }^{2}$ Gain clamping can be achieved by introducing laser action through wavelength selective feedback using distributed Bragg reflectors. During laser operation, the round trip gain is fixed to unity, and therefore the single-pass gain itself is fixed irrespective of the input power. This principle has been applied with success to reduce signal distortion in analog SOAs. ${ }^{3}$ In addition, gain clamping shows significant cross-talk reduction in SOAs used in WDM systems. ${ }^{4}$ Other issues such as polarization insensitive amplification have been largely resolved by the use of combinations of TE (compressive) and TM (tensile) strained quantum wells, and square or tensile strained bulk-active layers.

The feasibility of SOAs is being investigated in various system trials. Encouraging results have been demonstrated by several groups both in the 1.3 - and $1.5-\mu \mathrm{m}$ windows. Semiconductor optical amplifiers are part of the answer towards the new functionality that advanced fiber-optic systems require.

1. L.F. Tiemeijer, P.J.A. Thijs, T. van Dongen, J.J.M. Binsma, E.J. Jansen, J. Lightwave Technol. 14, 1524-1533 (1996).

2. L.F. Tiemeijer, G.N. van den Hoven, P.J.A. Thijs, T. van Dongen, J.J.M. Binsma, E.J. Jansen, IEEE Photon. Technol. Lett. 8, 1453-1455 (1996).

3. V.G. Mutalik, G.N. van den Hoven, L.F. Tiemeijer, in Optical Fiber Communication Conference, Vol. 6 of 1997 OSA Technical Digest Series (Optical Society of America, Washington, D.C., 1997), pp. 266-267.
4. M. Bachmann, P. Doussière, J.Y. Emery, R. N'Go, F. Pommereau, L. Goldstein, G. Soulage, A. Jourdan, Electron. Lett., 32, 2076-2078 (1996).

TuH2

2:30pm

Detailed experimental and theoretical investigation and comparison of the cascadability of semiconductor optical amplifier gates and gain-clamped semiconductor optical amplifier gates

S.L. Danielsen, P.B. Hansen, D. Wolfson, B. Mikkelsen, K.E. Stubkjaer, J.Y. Emery,* F. Pommereau,* M. Renaud,* Technical University of Denmark, Department of Electromagnetic Systems, Center for Broadband Telecommunications, Building 349, Technical University of Denmark, DK-2800 Lyngby, Denmark; E-mail: sdl@emi.dtu.dk

Semiconductor optical amplifiers (SOAs) are attractive for space switching because they have up to $30 \mathrm{~dB}$ gain ${ }^{1}$ and high on-off ratios of $40-50 \mathrm{~dB}$ that are required to overcome crosstalk induced penalty. ${ }^{2} \mathrm{SOA}$ gates do, however, have a limited input power dynamic range (IPDR) and thus limited cascadability caused by amplified spontaneous emission (ASE) and by gain saturation that leads to extinction ratio degradation. ${ }^{3}$ The influence of the latter can be reduced by using gain-clamped SOA gates (GC-SOA) for which the gain is clamped for operation above lasing threshold. ${ }^{4}$

Here, a detailed investigation of the cascadability of GC-SOAs is presented and compared to that of conventional SOAs for different bit rates. The analysis is both theoretical and experimental and shows that at $2.5 \mathrm{Gbit} / \mathrm{s}$ more than $30 \mathrm{GC}$-SOAs can be cascaded while only seven conventional SOAs (@1-dB penalty).

The superior performance of the GC-SOA is primarily the result of the saturation characteristics. These are illustrated in Fig. 1 for a 1000$\mu \mathrm{m}$-long GC-SOA (structure described in Ref. 5). Results for a $450-\mu \mathrm{m}$ long SOA (described in Ref. 3 ) are also shown. Note, the excellent agreement between measurements and theory. The gain of the GC-SOA

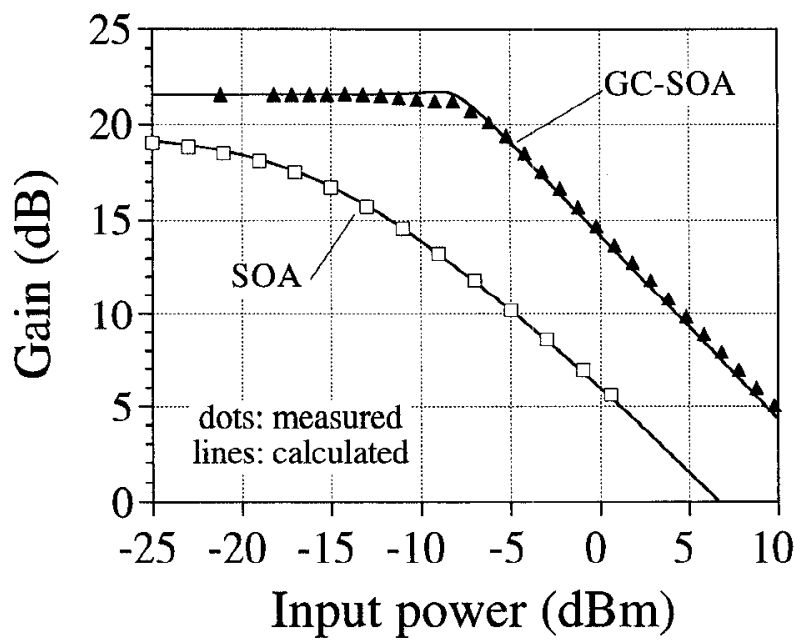

TuH2 Fig. 1. Measured (dots) and calculated (lines) gain versus input power for a $450-\mu \mathrm{m}$-long SOA gate operated at $40 \mathrm{~mA}$ and a $1000-\mu \mathrm{m}$-long GC-SOA operated at $200 \mathrm{~mA}$. The GC-SOA is realized as a DBR laser with two Bragg sections of lengths $200 \mu \mathrm{m}$ and an active section of length $600 \mu \mathrm{m}$. 
remains constant until the amplified signal power level becomes comparable to the power of the lasing mode. Therefore, the extinction ratio degradation due to gain saturation is reduced.

This is also seen in Fig. 2(a), showing a very high measured IPDR of $\sim 19 \mathrm{~dB}$ at $10 \mathrm{Gbit} / \mathrm{s}$ (taken at $2 \mathrm{~dB}$ penalty because a pre-amplified receiver is used). For a conventional SOA gate the usable IPDR is $10-15$ $\mathrm{dB}$ at the same bit rate. ${ }^{3}$ At $15 \mathrm{Gbit} / \mathrm{s}$ the IPDR for the GC-SOA is reduced. At low input powers this is due to a higher required signal-toASE ratio. At high input powers, bit patterning due to the relaxation oscillations of the lasing GC-SOA causes limitations that get more pronounced at higher bit rates as clearly illustrated in Fig. 2(b) by the 15 Gbit/s pulse trace. Still, operation at $10 \mathrm{Gbit} / \mathrm{s}$ is sufficient for most network applications planned today.

In networks several gates must be cascaded. In the following we present a theoretical analysis of the cascadability of GC-SOA and conventional SOA gates. To make a fair comparison equal gains of $20 \mathrm{~dB}$ are used. Additionally, equal signal-to-ASE ratios are ensured with an input power to the GC-SOA of $-15 \mathrm{dBm}$ (noise figure is $\sim 11 \mathrm{~dB}$ ) and $-21 \mathrm{dBm}$ to the $S O A$ (noise figure is $\sim 5 \mathrm{~dB}$ ). Figure 3 shows the penalty and extinction ratio versus the number of cascaded gates at 2.5 and $10 \mathrm{Gbit} / \mathrm{s}$. At $2.5 \mathrm{Gbit} / \mathrm{s}$ more than $30 \mathrm{GC}-\mathrm{SOAs}$
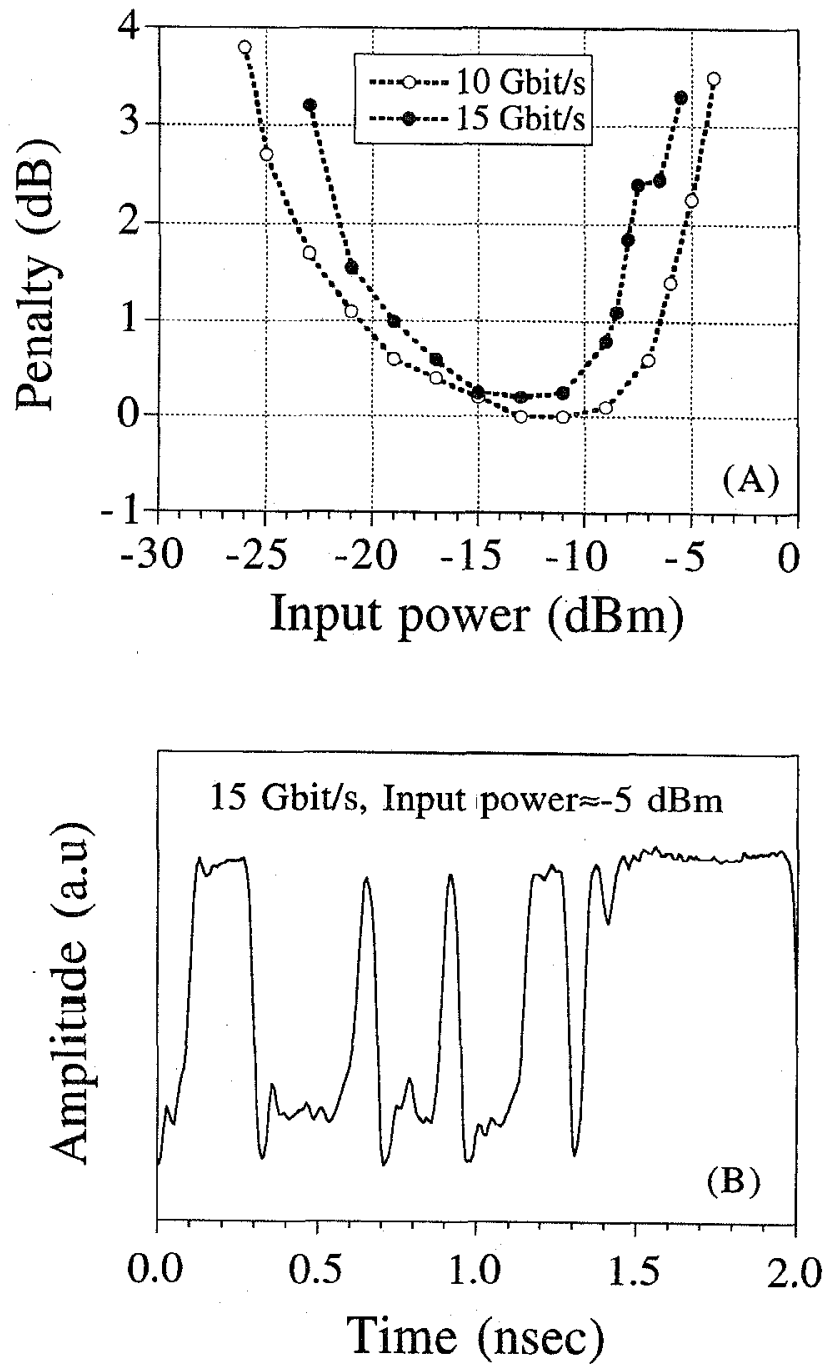

TuH2 Fig. 2. (a) Measured penalty (pre-amplified) versus input power for a $1000-\mu \mathrm{m}$-long GC-SOA operated at $200 \mathrm{~mA}$. Results are given at 10 and $15 \mathrm{Gbit} / \mathrm{s}$. (b) Measured pulse trace for gated signal at $15 \mathrm{Gbit} / \mathrm{s}$ at an input power of $\approx-5 \mathrm{dBm}$.

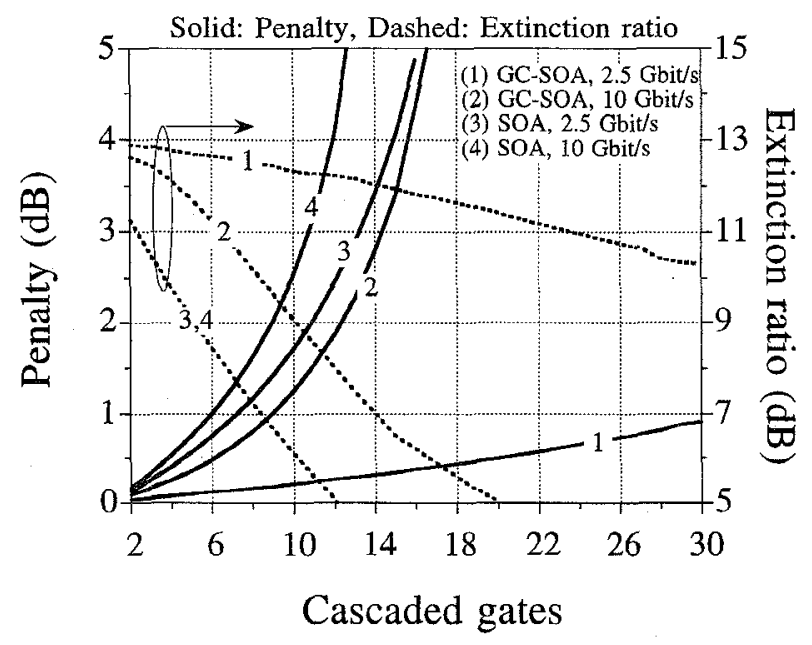

TuH2 Fig. 3. Theoretical investigation of the cascadability at 2.5 and $10 \mathrm{Gbit} / \mathrm{s}$ for SOA an GC-SOA gates. The gain for both gates is $20 \mathrm{~dB}$. The input power to the SOA gate is $-21 \mathrm{dBm}$ while $-15 \mathrm{dBm}$ to the GC-SOA.

can be cascaded with a penalty $<1 \mathrm{~dB}$. This is far superior compared to the conventional SOA for which the cascadability is limited to $\sim 7$ gates at 2.5 Gbit/s. Furthermore, it is noted, that even at $10 \mathrm{Gbit} / \mathrm{s}$ where the accumulation of ASE starts to become a factor and where the influence of relaxation oscillations sets in, the number of GC-SOAs that can be cascaded is higher than for the SOA at $2.5 \mathrm{Gbit} / \mathrm{s}$.

In conclusion, the effective gain clamping and thereby limited extinction ratio degradation of GC-SOA gates make them attractive for network applications where high switching speeds and cascadability are required.

*Alcatel Corporate Research Center, clo Alcatel Alsthom Recherche, Route de Nozay, F-91460 Marcoussis, France

1. P. Dousierre et al, in Optical Amplifiers and their Applications, Vol. 18 of 1995 OSA Technical Digest Series (Optical Society of America, Washington, D.C., 1995), pp. 119-122.

2. E. Goldstein et al., IEEE Photon. Technol. Lett. 6, 657-660 (1994).

3. B. Mikkelsen et al, in Proceedings of European Conference on Optical Communication (ECOC'94), 1994, pp. 710-713.

4. L. Lablonde et al., in Proceedings of European Conference on Optical Communication (ECOC'94), 1994, pp. 715-718.

5. G. Soulage et al., in Proceedings of European Conference on Optical Communication (ECOC'96), 1996, pp. 145-148.

Fast optical amplifier gate array for WDM routing and switching applications

F. Dorgeuille, B. Lavigne, J.Y. Emery, M. Di Maggio, J. Le Bris,

D. Chiaroni, M. Renaud, R. Baucknecht,* H.P. Schneibel,*

C. Graf,* H. Melchior,* Alcatel Alsthom Corporate Research Centre, c/o Alcatel Alsthom Recherche, Route de Nozay, 91460 Marcoussis, France; E-mail: francois.dorgeuille@aar.alcatel-alsthom.fr

Clamped-gain semiconductor optical amplifiers (CG-SOAs) have already demonstrated their great potential for fast optical space switching of wavelength-division multiplexing (WDM) channels both in cross- 